\title{
Preparation of Copolymer of 2-Methacryloyloxyethyldimethyl-3-sulfonic Acid Propylammonium Hydroxide and 3-(Methacryloyloxy) Propyltrimethoxysilane and Its Dye Adsorption Properties
}

\author{
Fenfen Xi*, Liping Liang*, Weishou Tan*, Yanyan Dong*, Linshuang Yu*, Huiting Ma*, Gaosheng Yue****† \\ and Xu Meng*(**) $(* * *) \dagger$ \\ *College of Life Science, College of Textile and Garment, Shaoxing University, Shaoxing, China \\ **Key Laboratory of Clean Dyeing and Finishing Technology of Zhejiang Province, Shaoxing University, \\ Shaoxing, China \\ ***Zhejiang Sub-center of National Carbon Fiber Engineering Technology Research Center, Shaoxing, China \\ ****Zhejiang Transchem Chemical Co. Ltd., Hangzhou, 311215, China \\ †Corresponding author. Gaosheng Yue; yuegaosheng2012@163.com, Xu Meng; mengqiaoshen@163.com
}

Nat. Env. \& Poll. Tech.

Website: www.neptjournal.com

Received: 26-02-2021

Revised: 25-04-2021

Accepted: 01-05-2021

Key Words:

Dyeing wastewater

Treatment

Adsorption

Dyes

Polymer gel

\section{ABSTRACT}

While printing and dyeing bring us huge economic benefits, it also brings us huge challenges. Printing and dyeing will produce a large amount of wastewater, and the treatment of printing and dyeing wastewater has always been a concern. This work uses 2-methacryloxyethyl dimethyl-3-sulfonic acid propyl ammonium hydroxide, 3-(methacryloxy) propyl trimethoxysilane, and N, N'-methylene bispropylene as raw materials, and a photoinitiator is used to initiate polymerization under an ultraviolet lamp to prepare a copolymer gel. Taking the aqueous solution containing soap yellow as simulated dye wastewater, the adsorption performance of the prepared polymer for dyes was investigated. An ultraviolet spectrophotometer was used to investigate the effects of adsorption time, initial dye concentration, and polymer dosage on the adsorption performance. The performance test results show that the prepared polymer has high adsorption and removal efficiency for dyes containing soap yellow simulation, and has a potential application value.

\section{INTRODUCTION}

While printing and dyeing bring us huge economic benefits, it also brings us huge challenges (Ajmal et al. 2014). The printing and dyeing process of textile factories in traditional industries is a major discharger of industrial sewage (Liu et al. 2019). Most of the pollutants in the sewage come from various dyes, slurries, surfactants, auxiliaries, acids, and alkalis in the textile manufacturing process (Khan \& Lo 2016). Most of these additives are toxic and harmful, with complex impurities, diverse ingredients, and obvious differences in water quality, threatening the ecological environment and human health, and they are very difficult to deal with industrial pollution (Mittal et al. 2016).

For many years, people have been committed to the treatment of dye wastewater, and many methods have been discussed around how to quickly, effectively, scientifically, and environmentally solve the problem of dye wastewater. Treatment methods include coagulation precipitation method (Chethana et al. 2016, Dotto et al. 2019), membrane separation technology (Şen et al. 2018, Hosseini et al. 2018), ultrasonic oxidation method (Zia et al. 2019, Wang et al. 2019), photocatalytic oxidation method (Stock et al. 2000), micro electrolysis method (Han et al. 2016), biological treatment method (Paz et al. 2017) and adsorption method (Yagub et al. 2014), etc. Each of these methods has certain shortcomings, such as complicated procedures, a high proportion of chemical costs, complex technology, and a large number of impurities after treatment (Monier et al. 2010, Varaprasad et al. 2017). And with the development of chemical fibers and the increasing requirements for finishing after printing and dyeing, a large number of refractory organics such as pulp, new dyes, and chemical auxiliaries enter the textile printing and dyeing wastewater, posing a serious challenge to the traditional wastewater treatment process. Therefore, the development of new materials for dye treatment has become a research hotspot.

At present, people have conducted a lot of research on new materials for dye treatment, and have developed adsorbents with different properties and uses. Mittal et al. (Mittal et al. 2021) focused on the preparation of xanthan gum-based novel hydrogel nanocomposites via chemical crosslinking 
with graphene oxide for highly efficient adsorption of crystal violet dye from contaminated wastewater. With unique structure and properties, the composite is a great candidate for cationic dyes removal from wastewater. Vigneshwaran et al. (Vigneshwaran et al. 2021) successfully fabricated sulfur tethered adsorbent of Tapioca peel (S@TP) biochar and utilized it for the removal of organic dyes such as Malachite Green (MG) and Rhodamine B (RhB) from water. The newly fabricated bio-mass could be visualized as a capable adsorbent for the water/wastewater treatment process since the S@TP matrix possesses high removal and reusable efficiency towards dye molecules. Hydrogel has the characteristics of high separation efficiency and high selectivity in adsorption, and it is an adsorption method with good application prospects (Chaudhary et al. 2021, Binaeian et al. 2020, Marrakchi et al. 2020). The research results provide a feasible method for the separation of soluble dyes from dye waste liquid, and also provide a new idea for industrial wastewater purification.

In the work, 2-methacryloxyethyldimethyl-3-sulfonic acid propylammonium hydroxide, 3-(methacryloxy) propyltrimethoxysilane, and N, N'-methylene bis acrylamide cross-linking agent are used as raw material, and a photoinitiator is used to initiate polymerization under ultraviolet light to prepare a copolymer gel. Fig. 1 shows the schematic diagram of the preparation of copolymer gel. Use scanning electron microscope, Fourier transforms infrared spectrometer, thermogravimetric analyzer, and other instruments to characterize the surface morphology and chemical composition of the product. Taking the aqueous solution containing soap yellow as simulated dye wastewater, the adsorption performance of the prepared polymer for dyes was investigated. An ultraviolet spectrophotometer was used to investigate the effects of adsorption time, initial dye concentration, and polymer dosage on the adsorption performance. The performance test results show that the prepared polymer has high adsorption and removal efficiency for dyes containing soap yellow simulation, and has a potential application value.

\section{MATERIALS AND METHODS}

\section{Materials}

2-methacryloxyethyl dimethyl-3-sulfonic acid propyl ammonium hydroxide, 3-(methacryloxy) propyl trimethoxysilane, and $\mathrm{N}, \mathrm{N}^{\prime}$-methylene bispropylene were procured from Aladdin Industrial Inc., Shanghai, China.

\section{Preparation of Copolymer Gel}

Add $0.5 \mathrm{~g}$ of 2-methacryloyloxyethyldimethyl-3-sulfonic acid propylammonium hydroxide, $0.05 \mathrm{~g}$ of $\mathrm{N}, \mathrm{N}$ '-methylenebisacrylamide, and $0.05 \mathrm{~g}$ of 3-(Methacryloyloxy) propyltrimethoxysilane, dissolved in $30 \mathrm{~mL}$ of distilled water, irradiated under UV light for about $2 \mathrm{~h}$. A colloidal gel solid can be obtained, which is then dried in a freeze dryer to obtain the final product.

\section{Characterization}

After spraying a gold film with an ion sputtering instrument, the microstructure of the samples was characterized by an SNE-15000X scanning electron microscope (SEC, Korea). The composition of the polymer was analyzed by the Fourier transform infrared spectrometer (FTIR, Japan IRPrestige-21) with a wavelength range of $500-4000 \mathrm{~cm}^{-1}$. The thermal stability was demonstrated via the thermogravimetric/ differential thermal comprehensive analyzer (TG, Japan TG/DTA6300), which heated from $25^{\circ} \mathrm{C}$ to $700^{\circ} \mathrm{C}$ with a heating rate of $10^{\circ} \mathrm{C} \cdot \mathrm{min}^{-1}$ in an air atmosphere. The UV absorption of the dye was tested by a UV spectrophotometer (UV2600, Japan).

\section{Effect of Adsorption Time on Dye Adsorption Performance}

The polymer was used to adsorb $5 \mathrm{mg} . \mathrm{L}^{-1}$ soap yellow dye solution, and the UV-visible spectrophotometer was used to perform adsorption on the solution after $10 \mathrm{~min}, 20 \mathrm{~min}, 30$

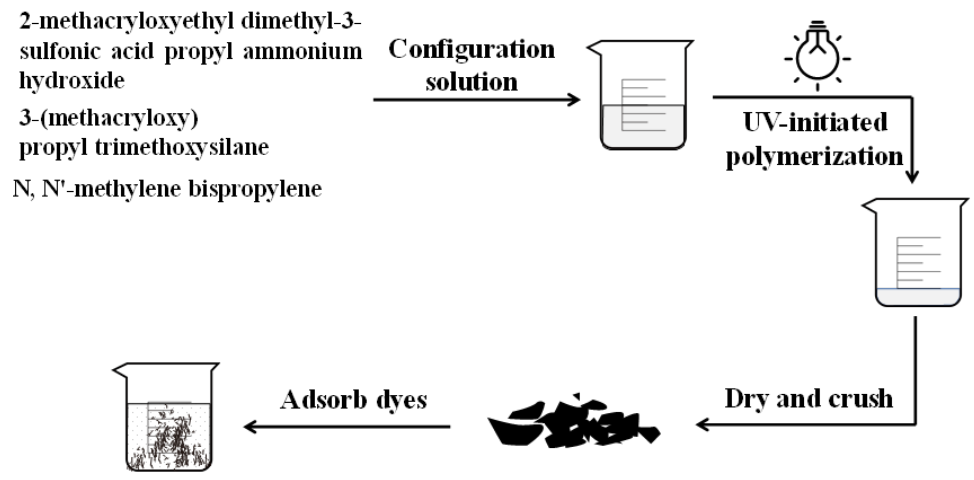

Fig. 1: Schematic diagram of the preparation of copolymer gel. 
min, $40 \mathrm{~min}, 50 \mathrm{~min}, 60 \mathrm{~min}, 120 \mathrm{~min}, 240 \mathrm{~min}, 480 \mathrm{~min}$, etc. The purpose of this experiment is to see how adsorption duration affects dye adsorption performance.

\section{Effect of Initial Dye Concentration on Adsorption Performance}

The aqueous solution containing soap yellow dye was used as simulated dye wastewater, and the initial concentrations were $0.4,1.2,5.0$, and $10.0 \mathrm{mg} . \mathrm{L}^{-1}$ dye respectively. The effect of the initial concentration of dye on the adsorption performance was investigated.

\section{Impact of Polymer Dosage on Adsorption Performance}

An aqueous solution containing $5 \mathrm{mg} . \mathrm{L}^{-1}$ of soap yellow dye was used as simulated dye wastewater. Under the condition of immersion for the same time, the effect of polymer dosage on adsorption performance was investigated.

\section{RESULTS AND DISCUSSION}

\section{FTIR Spectrum Analysis}

The infrared spectrum of the prepared polymer product is shown in Fig. 2. The absorption peak at $615 \mathrm{~cm}^{-1}$ in the spectrum may be due to the out-of-plane bending vibration of $\mathrm{C}-\mathrm{H}$. The absorption peak near $1196 \mathrm{~cm}^{-1}$ is presumably caused by the vibration of the $\mathrm{C}-\mathrm{C}$ framework or the stretching vibration of $\mathrm{C}-\mathrm{O}$. The absorption peak at $1713 \mathrm{~cm}^{-1}$ may be the vibration of $\mathrm{C}=\mathrm{O}$, and the absorption peak at $2961 \mathrm{~cm}^{-1}$ should be the contraction vibration of $-\mathrm{CH}_{2}$. From the experimental results, there are a variety of functional groups on the polymerized hydrogel. The existence of these functional groups makes the adsorption performance more excellent and has a better effect on the adsorption of dyes in dye wastewater.

\section{Surface Morphology Analysis of Synthetic Polymers}

The surface morphology is characterized by a scanning

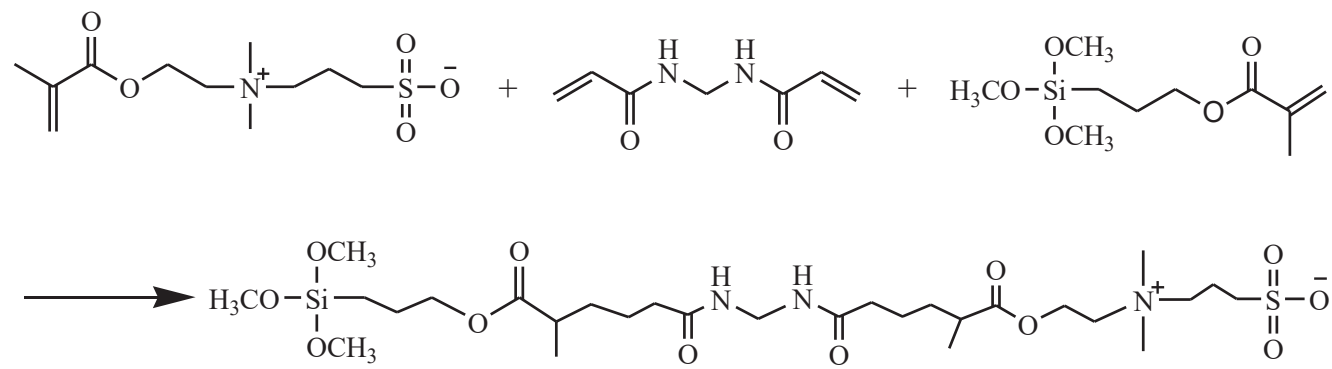

Scheme 1 polymerization equation of copolymer gel.

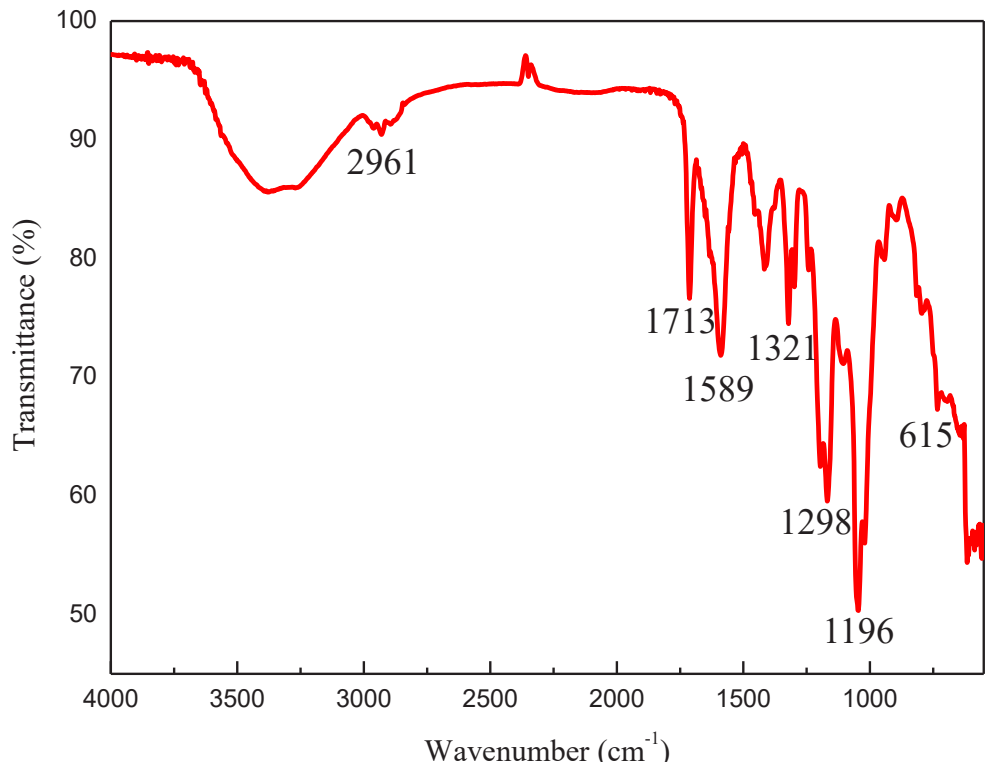

Fig. 2: FTIR spectrum of synthetic polymer. 
electron microscope, which can directly observe the fine structure of the material surface. To prevent changes in the structure and pore morphology of the gel, the polymerized gel is freeze-dried, and the water in the gel is directly sublimated to avoid the decomposition of the gel and the destruction of the gel structure. Generally, the adsorption phenomenon occurs on the surface of the adsorbent or inside the pores of the fibers. The physical structure of the adsorbent, such as the pore size and specific surface area, has a greater influence on the adsorption. Fig. 3 is an electron micrograph of synthetic polymer. The results show that the appearance of the polymer particles with pores is rough. The prepared polymer has a uniform spatial structure and a relatively large specific surface area, which greatly improves its adsorption performance. These pores can increase the contact area with the dye and can more effectively improve the adsorption performance of the product.

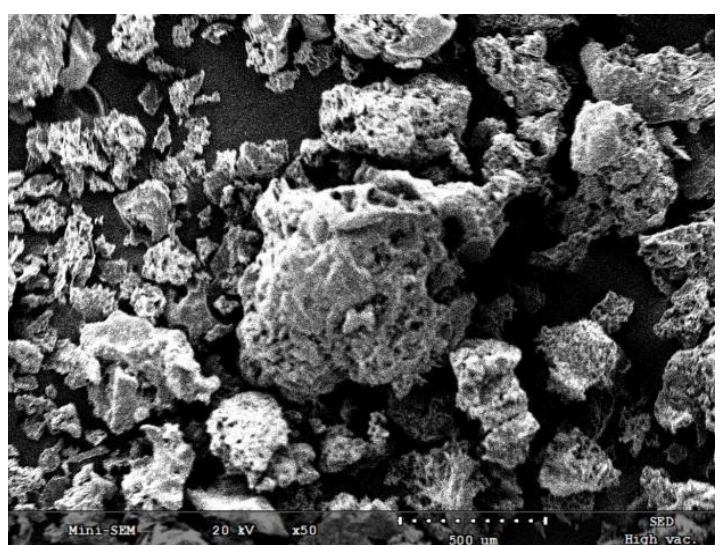

Fig. 3: Surface topography of synthetic polymer.

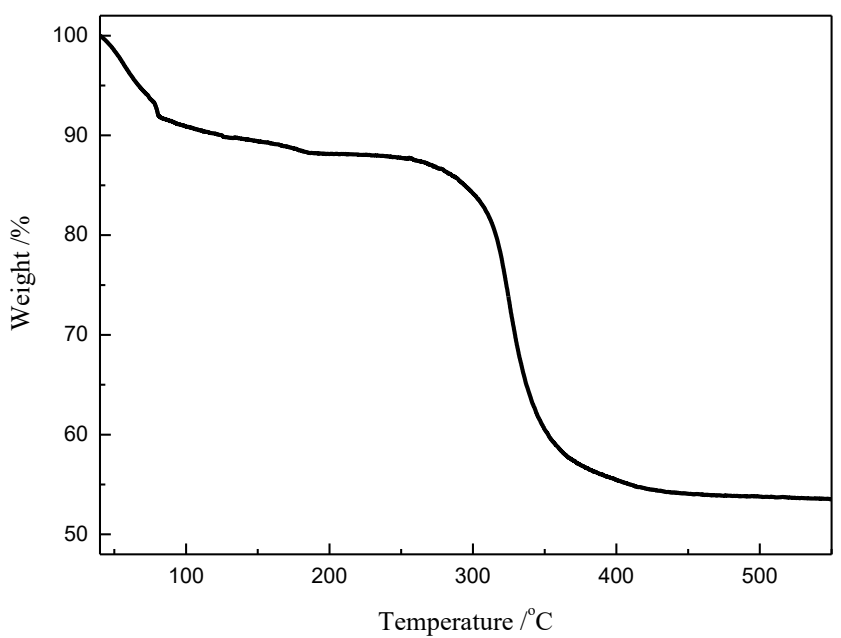

Fig. 4: Thermogravimetric analysis diagram of synthetic polymer.

\section{Thermogravimetric Analysis}

When investigating the thermal stability of the polymer, the initial temperature is set to $40^{\circ} \mathrm{C}$, the final temperature is $600^{\circ} \mathrm{C}$, and the selected gas is air. Fig. 4 shows the thermogravimetric analysis of the synthetic polymer. It can be seen from the results that the mass loss rate of the gel particles is relatively low at $40-120^{\circ} \mathrm{C}$. The mass change is relatively stable between $120^{\circ} \mathrm{C}$ and $270^{\circ} \mathrm{C}$, and the loss rate is relatively small; while the mass of the polymer over $280^{\circ} \mathrm{C}$ begins to increase. The range is reduced, and the material is decomposed in a large amount. When the temperature reaches $360^{\circ} \mathrm{C}-600^{\circ} \mathrm{C}$, the material mass loss efficiency is small and tends to be flat. It can be seen from the results that the synthesized polymer has good thermal stability before $280^{\circ} \mathrm{C}$.

\section{Effect of Adsorption Time on Dye Adsorption Performance}

Configure a $1.2 \mathrm{mg} . \mathrm{L}^{-1}$ soap yellow dye solution, measure $5 \mathrm{~mL}$ of the dye solution, and a polymer dosage of $0.015 \mathrm{~g}$ to study the effect of different adsorption times on the dye adsorption performance. The time gradient is set to $10 \mathrm{~min}$, $20 \mathrm{~min}, 30 \mathrm{~min}, 40 \mathrm{~min}, 50 \mathrm{~min}, 60 \mathrm{~min}, 120 \mathrm{~min}, 240 \mathrm{~min}$, $480 \mathrm{~min}$, the results are shown in Fig. 5. The results showed that the adsorption capacity of the synthetic polymer to the soap yellow dye increased with time. In a relatively short period of time, the increase in the amount of adsorption is larger and the adsorption efficiency is fast; with the increase of time, the increase in the amount of adsorption gradually tends to be flat and the adsorption rate becomes slower. This is mainly due to the attraction between the synthetic polymer and the dye molecule so that the anionic dye is adsorbed on the polymer at a faster speed. As the adsorption sites on the synthetic polymer gradually bind to the dye molecules, the

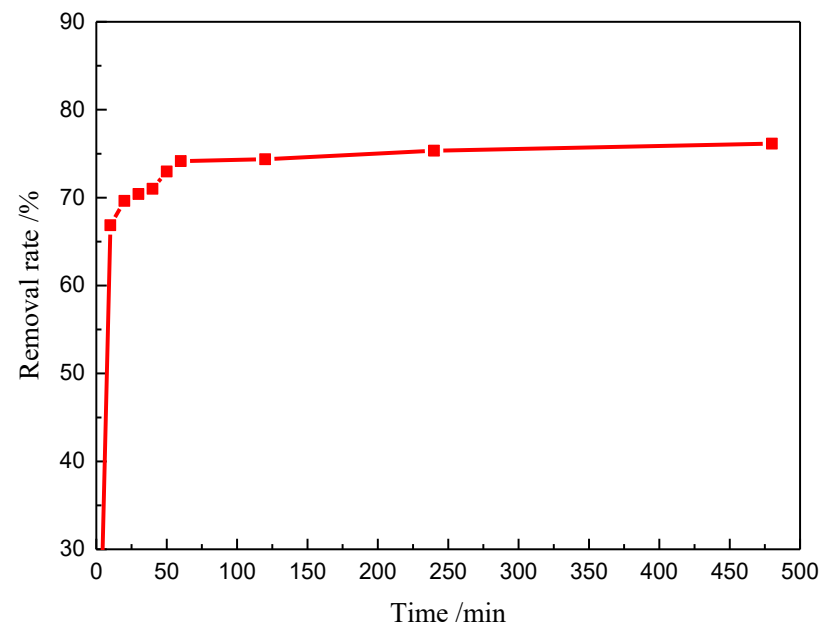

Fig. 5: The effect of adsorption time on dye adsorption performance. 
adsorption sites are reduced, the driving force of adsorption is weakened, and the subsequent adsorption rate is reduced. It shows that the adsorption speed of the prepared polymer is faster, and the utility can be realized in a shorter time.

\section{Effect of Initial Dye Concentration on Adsorption Performance}

Weigh $0.015 \mathrm{~g}$ of the polymer as the adsorbent, add it to the dye solution with an initial concentration of $0.4,1.2,5.0$, $10.0 \mathrm{mg} . \mathrm{L}^{-1}$, respectively. The amount of dye solution is 5 $\mathrm{mL}$, and the adsorption time is $10 \mathrm{~min}$. The effect of initial dye concentration on adsorption performance is shown in Fig. 6. The results show that under the conditions of different initial dye concentrations, as the dye concentration increases, the driving force continues to increase, the chance of the polymer contacting dye molecules increases, and more dye molecules can be adsorbed on the polymer, which increases the adsorption capacity. However, with the further increase of the dye concentration, the absorption rate of the polymer to the dye decreases. This is because the adsorption sites on the polymer are already occupied by the dye molecules, and the adsorption capacity decreases. Among them, the dye adsorption quantity is calculated by the formula.

$$
\mathrm{Q}_{\mathrm{t}}=\left(\mathrm{C}_{0}-\mathrm{C}_{\mathrm{t}}\right) \mathrm{V} / \mathrm{M}
$$

Among them, $\mathrm{C}_{0}$ is the concentration of initial dye, $m g \cdot L^{-1} \cdot C_{t}$ is the concentration of dye in solution at time $t$, $\mathrm{mg} \cdot \mathrm{L}^{-1} . \mathrm{V}$ is the volume of dye solution, $\mathrm{L} . \mathrm{M}$ is the mass of modified synthetic adsorbent, $\mathrm{g}$. The adsorption capacity of the adsorbent for dye at $Q_{t}-t$ time, mg.g ${ }^{-1}$.

\section{Impact of Polymer Dosage on Adsorption Performance}

A $1.2 \mathrm{mg} . \mathrm{L}^{-1}$ soap yellow dye solution was prepared, and 5

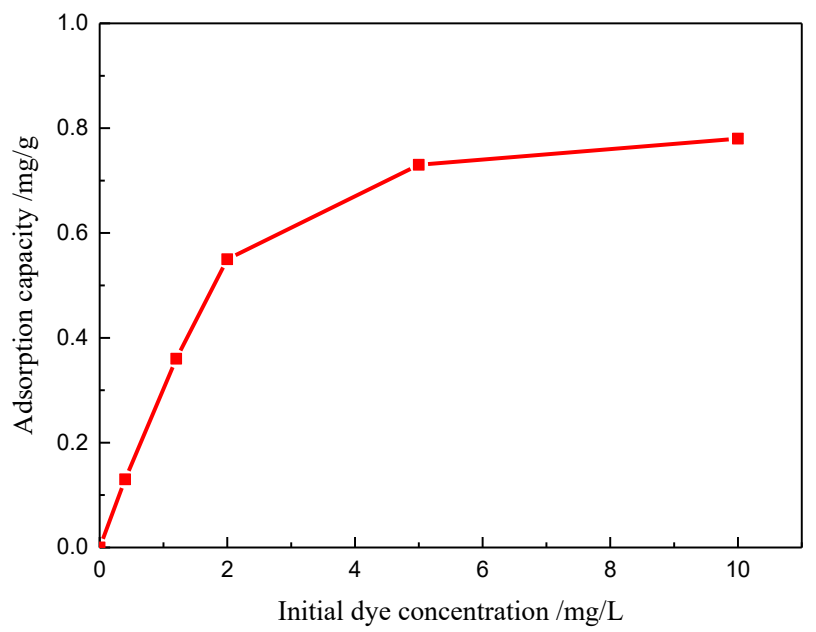

Fig. 6: The effect of initial dye concentration on adsorption performance.
$\mathrm{mL}$ of the dye solution was measured. The polymer dosages were $5,10,15,20$, and $25 \mathrm{mg}$, respectively. The effect of the polymer dosage on the adsorption performance was studied. The results are as follows shown in Fig. 7. The adsorption rate of dyes gradually increased with the increase of polymer dosage. When the dosage of the polymer is less than $15 \mathrm{mg}$, the adsorption rate of the dye increases rapidly. When the dosage of the polymer is greater than $15 \mathrm{mg}$, the increase in the absorption rate of the dye is smaller. This is because increasing the dosage of the polymer can increase the available adsorption sites, thereby increasing the dye adsorption rate. However, when the dosage of the polymer exceeds 15 $\mathrm{mg}$, the dye in the solution is adsorbed and removed by the polymer, and the excess adsorption sites are not used, which makes the adsorption rate decrease.

\section{CONCLUSION}

This work uses 2-methacryloxyethyldimethyl-3-sulfonic acid propylammonium hydroxide, 3-(methacryloxy)propyltrimethoxysilane, and N, N'-methylene bis acrylamide crosslinking agent as the raw material, and the copolymer gel is prepared by a photoinitiator under ultraviolet light to initiate polymerization. Use scanning electron microscope, Fourier transforms infrared spectrometer, thermogravimetric analyzer, and other instruments to characterize the surface morphology and chemical composition of the product. It can be seen from the SEM image that the polymer has a uniform spatial structure and a relatively large specific surface area, so the prepared polymer has excellent adsorption performance and can quickly and effectively absorb the dye in the dyeing solution. An ultraviolet spectrophotometer was used to investigate the effects of adsorption time, initial dye concentration, and polymer dosage on the adsorption

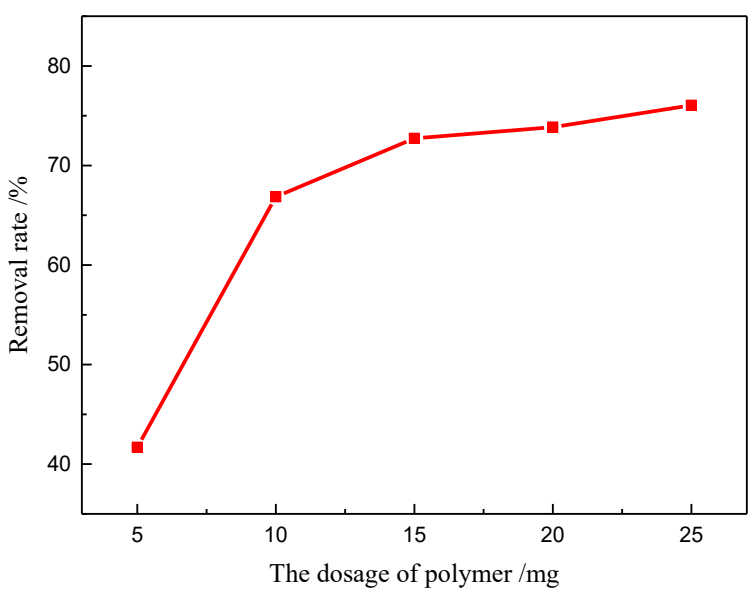

Fig. 7: The effect of polymer dosage on adsorption performance. 
performance. The results show that the prepared polymer has a higher adsorption removal rate and a faster adsorption rate for dyes containing soap yellow simulation, and has a potential application value.

\section{ACKNOWLEDGEMENT}

The authors gratefully acknowledge the financial support of the International Science and Technology Cooperation Project of Shaoxing University (Grant No. 2019LGGH1004).

\section{REFERENCES}

Ajmal, A., Majeed, I., Malik, R.N., Idriss, H. and Nadeem, M.A. 2014. Principles and mechanisms of photocatalytic dye degradation on $\mathrm{TiO}_{2}$ based photocatalysts: a comparative overview. RSC Adv., 4: 37003-37026.

Binaeian, E., Babaee Zadvarzi, S. and Yuan, D. 2020. Anionic dye uptake via composite using chitosan-polyacrylamide hydrogel as matrix containing $\mathrm{TiO}_{2}$ nanoparticles; comprehensive adsorption studies. Int. J. Biol. Macromol., 162: 150-162.

Chaudhary, J., Thakur, S., Mamba, G., Prateek, Gupta, R.K. and Thakur, V.K. 2021. The hydrogel of gelatin in the presence of graphite for the adsorption of dye: Towards the concept for water purification. J. Environ. Chem. Eng., 9: 104762.

Chethana, M., Sorokhaibam, L.G., Bhandari, V.M., Raja, S. and Ranade, V.V. 2016. Green approach to dye wastewater treatment using biocoagulants. ACS Sust. Chem. Eng., 4: 2495-2507.

Dotto, J., Fagundes-Klen, M.R., Veit, M.T., Palácio, S.M. and Bergamasco, R. 2019. Performance of different coagulants in the coagulation/flocculation process of textile wastewater. J. Cleaner Prod., 208: 656-665.

Han, Y., Li, H., Liu, M., Sang, Y., Liang, C. and Chen, J. 2016. Purification treatment of dyes wastewater with a novel micro-electrolysis reactor. Sep. Purif. Technol., 170: 241-247.

Hosseini, S.A., Vossoughi, M., Mahmoodi, N.M. and Sadrzadeh, M. 2018. Efficient dye removal from aqueous solution by high-performance electrospun nanofibrous membranes through incorporation of $\mathrm{SiO}_{2}$ nanoparticles. J. Cleaner Prod., 183: 1197-1206.

Khan, M. and Lo, I.M.C. 2016. A holistic review of hydrogel applications in the adsorptive removal of aqueous pollutants: Recent progress, challenges, and perspectives. Water Res., 106: 259-271.

Liu, H., Yu, D., Sun, T., Du, H., Jiang, W., Muhammad, Y. and Huang, L. 2019. Fabrication of surface alkalinized $g-\mathrm{C}_{3} \mathrm{~N}_{4}$ and $\mathrm{TiO}_{2}$ composite for the synergistic adsorption-photocatalytic degradation of methylene blue. Appl. Surf. Sci., 473: 855-863.

Marrakchi, F., Hameed, B.H. and Hummadi, E.H. 2020. Mesoporous biohybrid epichlorohydrin crosslinked chitosan/carbon-clay adsorbent for effective cationic and anionic dyes adsorption. Int. J. Biol. Macromol., 163: 1079-1086

Mittal, H., Al Alili, A., Morajkar, P.P. and Alhassan, S.M. 2021. Graphene oxide crosslinked hydrogel nanocomposites of xanthan gum for the adsorption of crystal violet dye. J. Mol. Liq., 323: 115034.

Mittal, H., Maity, A. and Ray, S.S. 2016. Gum karaya based hydrogel nanocomposites for the effective removal of cationic dyes from aqueous solutions. Appl. Surf. Sci., 364: 917-930.

Monier, M., Ayad, D.M., Wei, Y. and Sarhan, A. 2010. Adsorption of Cu(II), $\mathrm{Co}(\mathrm{II})$, and $\mathrm{Ni}(\mathrm{II})$ ions by modified magnetic chitosan chelating resin. J. Hazard. Mater., 177: 962-970.

Paz, A., Carballo, J., Pérez, M.J. and Domínguez, J.M. 2017. Biological treatment of model dyes and textile wastewaters. Chemosphere, 181: 168-177.

Sen, F., Demirba , Ö., Çalımlı, M.H., Aygün, A., Alma, M.H. and Nas, M.S. 2018. The dye removal from aqueous solution using polymer composite films. Appl. Water Sci., 8: 206.

Stock, N., Peller, J., Vinodgopal, K. and Kamat, P. 2000. Combinative sonolysis and photocatalysis for textile dye degradation. Environ. Sci. Technol., 34: 114

Varaprasad, K., Jayaramudu, T. and Sadiku, E.R. 2017. Removal of dye by carboxymethyl cellulose, acrylamide, and graphene oxide via a free radical polymerization process. Carbohydr. Polym., 164: 186-194.

Vigneshwaran, S., Sirajudheen, P., Karthikeyan, P. and Meenakshi, S. 2021. Fabrication of sulfur-doped biochar derived from tapioca peel waste with superior adsorption performance for the removal of Malachite green and Rhodamine B dyes. Surf. Interfaces, 23: 100920.

Wang, J., Wang, Z., Vieira, C.L.Z., Wolfson, J.M., Pingtian, G. and Huang, S. 2019. Review on the treatment of organic pollutants in water by ultrasonic technology. Ultrasonics Sonochemistry, 55: 273-278.

Yagub, M.T., Sen, T.K., Afroze, S. and Ang, H.M. 2014. Dye and its removal from aqueous solution by adsorption: A review. Advances in Colloid and Interface Science, 209: 172-184.

Zia, J., Ajeer, M. and Riaz, U. 2019. Visible-light driven photocatalytic degradation of bisphenol-A using ultrasonically synthesized polypyrrole/K-birnessite nanohybrids: Experimental and DFT studies. Journal of environmental sciences (China), 79: 161-173. 